\title{
Should humans work?
}

\author{
Sergio Santos ${ }^{1-3}$, Maritsa Kissamitaki $^{1}$, Matteo Chiesa ${ }^{2,4}$ \\ ${ }^{1}$ Future Synthesis AS Uniongata 18, 3732 Skien, Norway \\ ${ }^{2}$ Arctic Renewable Energy Center (ARC), Department of Physics and Technology, UiT, Norway \\ ${ }^{3}$ Departament d'Enginyeria de Mines, Industrial i TIC (EMIT), Universitat Politècnica de Catalunya \\ (UPC), Av. Bases, 61, 08242 Manresa (Barcelona), Spain \\ ${ }^{4}$ Laboratory for Energy and NanoScience (LENS), Khalifa University of Science and Technology, \\ Masdar Institute Campus, Abu Dhabi, UAE
}

Declarations of interest: none.

Corresponding author address:

Sergio Santos

Future Synthesis AS Uniongata 18, 3732 Skien, Norway

ssantos@theopeninstituteofmind.org 


\begin{abstract}
Should humans work? A simple question at a time when the advent of Al, automation and robotics claims a privileged position in the future of work. The question is perplexing and confusing however once we inquire into the meaning of technology and work as such: some claim that human jobs and well-being might be threatened by technological advances while others predict an increase in high skilled demand. In short, we claim that standard debates obfuscate the question. That is, while animating the debate, standard arguments are instrumental to avoiding confrontation with the fundamental relation between humans, technology and work, namely, our position regarding what to do with technology and work, i.e. humans are "absent" in an "advancing" environment. We propose that focusing debates on the advantages and disadvantages of the development of advanced technology with the potential to do any human task does not necessarily clarify the situation, but rather unveils the obscurity of our relationship with technology by illuminating the lack of clarification.
\end{abstract}

Keywords: technology, human, work, Al, automation

\title{
1. Introduction
}


It is said that with the advent of artificial intelligence (AI) many human jobs might be lost to machines. In some respect, we are already seeing it. Debates directly follow as to how to make up for lost jobs (Arntz, Gregory, \& Zierahn, 2017; Bessen, 2018). Some claim that with advanced technology the availability of jobs might increase instead (Autor, 2015; Bessen, 2016).That is, paradoxically, by producing technically better technology humans might get somehow "busier". Rather than clarifying the object of machines and technology per se and in relation to humans however, debates are pointing at targets by already presupposing such object and relation. The resulting state of affairs is perplexing at best. How can knowledge or its application be perceived as, or in fact claimed to be, negative in any way? We believe that it is more likely that debates lose their own reference while the question itself dilutes as its central object becomes inconspicuous. This line of thought leads directly to what the authors perceive to be a spurious entanglement between the practical side of the question "should humans work?", i.e. the outcome expected from "jobs" in the form of products, goods, services or similar, and what we, as humans, feel might be at stake. This results in a derailed detour to asking the question as such to rather viewing our jobs as a source of meaning, purpose or social structure and somehow providing an answer to the question of "who" we are within society.

Before we move on to discussing what we think are the most discussed problems in debates regarding work, technology and humans, let us briefly point out what we think is a typical starting point that precedes them and presupposes them. Namely, that humans must access commodities in order to survive while technology is meant to advance in efficiency and sophistication. These statements and similar determine both humans and technology without first clarifying the relationship between the two. Our claim is that most current arguments stand on top of assertions that presuppose the above in some, many times obscure, way. In short, we seem to already know what the most relevant questions are while we also seem to have a set of candidate answers already selected that presuppose what 
humans need and what technology must be. Here, it is the point of departure that we want to put to the test. A possible way to bring to the fore the obscurity of presuppositions consists in probing standard questions and answers in order that paradoxes and inconsistencies reveal themselves from within. In the rest of the article we are to show how questioning in the direction of such presuppositions reveals lack of clarity regarding our relationship with technology in a way that arguments seem to speak of a gap between humans and technology.

\section{Discussion}

\subsection{Human autonomy versus machine autonomy}

Links between meaning, purpose and outcome are tempting, but they can easily lead to confusion.

Suffice it to think this question: in what way can a machine that performs technically well and efficiently be negative? In any case, taking the definition of the term "work" or "job" broadly makes it particularly hard to remain neutral to the actual object of "paid jobs" and "human labor" and to the object of machines, automation and Al itself as opposed to how we claim they might affect society. One can broadly define work as any human "activity involving mental or physical effort done in order to achieve a purpose or result" in general (work, 2019). With this definition, we see how the question "should humans work?" could be easily perceived as conflictive by questioning whether humans should carry out any meaningful or purposeful activity at all. We hope that it is obvious that this is not our claim. We clarify at the outset that we want to inquire into "work", "jobs" or "paid jobs" in the narrower sense of a

"mental or physical activity as a means of earning income; employment" (work, 2019). Such definition is complete only if we emphasize the "as a means of earning income" in the sense that earning is a necessary part of the work. Furthermore, we clearly distinguish at once between what we get from this "work" in terms of income or money and the access that the latter provides to "basic needs" in a general 
way. That is, we refer to the "earning as a means to" access what, for the most part, we claim we need in order to survive with "dignity", i.e. humans require access to a list of "basic needs" (Jolly, 1976). We concede that the actual list and what should or should not be included in it is debatable, but we argue that such debate belongs to another investigation. Husserl famously quoted (Husserl, 2001) and approved of Kant's view on logic and judgement by saying "we do not augment, but rather subvert our field of work, if we allow boundaries to run together". In this sense, we believe that the object of our question should be posed by avoiding any possible detour toward other topics such as psychology, sociology or politics. In any case our concern here is the nature of producing and accessing these socalled "needs" in relation to "paid jobs" and machines and automation, not the actual list. In this sense we might simply, but generally, define them as those needs that we currently have access to in the modern world only if we have access to money. That is, as those goods that we can legally buy. A source of confusion would arise at once in defining "work itself" as a basic need since this would take us directly into an entanglement with the question of meaning. In fact, we believe that many are explicitly or implicitly making such claim. Keeping these issues in mind, in this article, we write terms particularly prone to confusion with quotation marks throughout as we actively trace changes in connotation or meaning while we inquire the object of each question or answer instead. We should add and hope that one should be overly pedantic to not understand our general but simple definition of "work", "paid work", payment, money, or similar other concepts, since we all use money daily and, for the most part, we understand what it means to buy goods with money. We also, for the most part, carry out many activities that we claim add meaning to our lives even though these are not paid. This is our broader definition of activity. The central simple question "should humans work?" is further founded in the question that allows us to formulate the question in the first place, since it is the question that generates expectation, hope and many times fear, namely, "can technology solve our practical technical problems of survival so working is not necessary?" This question easily turns into the question of 
whether "I am necessary" in general. Certainly, if we claim that we are necessary only in the way a machine produces, it looks like in the long run we will be at a loss. If technology is "the application of scientific knowledge for practical purposes" (technology, 2019)however, it also seems clear that technology can be geared toward solving our practical problems, not viewed as a menace. If we take this approach, asking the simple question "should humans work?" opens up another simple question "should we guide technology toward supporting our lives or toward threatening our lives?" Not asking this question is equivalent to leaving it to an arbitrary advance of technology to tell us the answer as things just happen.

A risk beyond terminology and denotation relates to prioritizing or overemphasizing the need of integrity in the sense of a unified view in the speech, logical consistency in the discourse or discussion and the requirement of completeness in the unfolding theory. Others might be obsessed with originality or lack thereof. Questioning however does not demand originality, but rather clarification. In short, such procedures do not talk of an open society that wants to face a problem directly from its foundation, but rather, tacitly dictate what the direction of the debate should be at the outset while advocating criticism at best, or simply generating confusion and chaos at worst. This last point was raised by Noam Chomsky who implied that similar procedures can be exploited to control society since they give "people the sense that there's free thinking going on" (Chomsky, 1998).It is our intention to emphasize these points critically at the outset because the problem of "work", and the practical aspect of machines efficiently carrying out tasks, gets easily entangled with the problem of discussing "work" in terms of vague concepts invoking the "meaning" of work to individuals, and more thoroughly, the actual relationship between "work" and "meaning". A simple example would be to prevent trucks from efficiently transporting merchandise since many humans would gain access to employment by carrying everything by hand instead. We could even argue that many might find "meaning" and "purpose" in 
such task. We could then "vividly argue" about the best way to carry merchandise manually, but the problem itself would have been already reduced to a ridicule. That is, at bottom, this type of argument poses an embarrassment. It should be clear that such example has little to do with meaning and purpose and much to do with a confused society instead in relation to "technology". It is also risky to bet on overcomplicating the scope of the topic or entering the sceptical game by claiming that the scope of the question is too broad and cannot be reduced to intelligible directions or paths. At bottom, these claims contain strong forms of scepticism regarding whether humans can decide their own future by clearly choosing a direction to follow, and, more fundamentally, the possibility to access, or even the existence of, such knowledge, direction or solution (Husserl, 2001). In this sense, not saying anything by blaming the complexity of the issue would be a particularly tempting form of sophistry on our side. If we are to ask the question attending with honesty to the possibilities only, such embarrassments might be avoided. We are still to argue however that a question with so many implications in society, i.e. sociology, economy, politics and the educational system and its aim (Garimella, 2018), should be set loose not only in terms of the spectrum to be investigated, but also in terms of depth. That is, we should not be afraid of the complications related to the question, or its relationship to personal "meaning" or survival, but rather, we should face it directly in order to decide our next move. That we are more concerned with advances in Al and automation than in clarifying what this advance actually means seems to support schools of thought such as Adorno's(Adorno, 1991) and Foucault's(Foucault, 1994). The sciences are ready to say that other than measurement and prediction, there are only ambiguous and obscure claims. More thoroughly, that "societal structures" such as governments, scientific journals, companies and educational institutions have a goal and that advancing Al algorithms and robotics, i.e. or similar current goals in the sciences, identify with such goal is at odds with the main concern of the average individual, i.e. survival and access to basic-needs or, more broadly, the comportment of society toward the individual but never the "advance" of algorithms or automated 
robots. Informally, worldwide, a main everyday question in people's minds is "how to survive" not whether a company will improve a current Al or automated system. This is irrespective of whether one might feel somehow excited about purchasing the new piece of advanced equipment. It rather seems that this state of affairs more readily confirms the statement of Foucault, namely, that the individual is absent in the goals of advancing structures claiming to advance society, i.e. an advancing society is already "autonomously" advancing without the individual. If this was not true, it would rather seem inconceivable that an "advancing technology" could threaten the means by which most of us hope to survive, i.e. our jobs, or that most would not immediately perceive technological advance as moving toward a better and more welcoming future. If anything, the current state of affairs reveals a gap between humans and their goals and advancing technology. In this sense, deciding our next move more clearly by facing the fundamental question of our relation to an advancing technology, and in particular the relationship between an advancing technological world and human work, is what is to provide "human autonomy" in a society were "machine autonomy" rather seems to replace the former priority wise.

\subsection{Advancing technology versus purposiveness}

To be sure, while ambiguity seems to surround the question of work and meaning, it seems rather clear that one of the technical questions is readily and for the most part understood in society, and more thoroughly by single individuals, today in the context of the advance of Al, robotics and automation. Namely, these disciplines could potentially reduce and possibly render human work obsolete. The central technical problem might be posed as a question; "is it technically possible to automate any human task?" Besides these technicalities, we all have expectations or are intrigued as to how these fields will finally unfold and fully integrate in society and, ultimately, what our position in it will be. In 
this sense, it also seems clear that people have pinned down the two central points of this question already in terms of how machines carrying out tasks can affect them personally in the positive or negative. Namely, 1) a technical question: not needing to work implies that the practical side of survival will have to be solved politically or technically. This implies we bet on technology for production. 2) A question of human purposiveness: what is it with purpose and meaning if we don't work? In the rest of the text we set to clarify and disentangle these two points. We emphasize however that the objective of our questioning is not to "disentangle" the meaning of working from working for a living, but rather, to bring to the fore the actual obscurity surrounding the relationship of humans with technology through such disentangling.

\subsection{The technical question and the question of meaning}

The technical question: In the technical question, people reduce the relation between "work-jobpayment" and "meaning" to a technicality. With this, some seem to claim that provided they can access any basic goods, i.e. "basic needs", including any human activity in the broad sense of the term work, they would not mind machines taking over their "paid jobs". That is, they would not mind being "replaced" in the sense that what is "meaningful" itself is not replaced. In principle these people would engage in activities anyway. In this sense the technical question looks at "activity" qua "activity" as what is meaningful. This is what we term meaning through "activity" qua "activity". That is, no exchange for money is needed for an activity to be meaningful. In this case, the modern concept of work would be a technicality that is required only because we "need it" for something else, but not for meaning itself. Meaning is to be found in the activity in a way that what determines meaning is the activity qua meaning. In summary, we can call this type of answer, or approach to work, a technical question since 
payment is required through work only as a practicality, but it does not affect the meaning of the activity itself. Finally, the technical question does not relate to what "should be done" in other than a purely technical way, i.e. reduce workload and increase well-being through technology, but rather to whether "it can be" done.

The question of meaning: While this might not be directly obvious, those claiming that humans should work, even if machines could technically carry out all human tasks, imply that "the activity of work together with the exchange" for work, i.e. money or other, is itself meaning. In this sense, it is not that we find meaning through work in something else. That is, work does not provide the means to meaning, since providing is always providing something else, but rather, working itself is meaning and purpose.

Convoluted answers: We further find that when answers seem convoluted, they typically link work as a technicality with work as meaning. In such cases, the answer can be separated into meaning and technicality by simply invoking the hypothetical case where machines could provide "anything" we need, i.e. "basic needs" to all. If we insist in "jobs" or "work" being meaningful even under these circumstances, we are in fact claiming that jobs themselves are meaningful. That is, the answer reduces to the "work-payment" relationship being itself "the meaning". On the other hand, if we claim, either in the hypothetical case of machines being able to produce anything or not, that it is best for people to do whatever they like, provided they have access to "basic needs", while we insist that we should work, we are introducing the concept of "meaning" into "work" in an obscure way. That is, we are claiming that we should still "work". There is a clear ambiguity here since "doing whatever we like", i.e. choosing what to do without the constraint of payment or lack of "basic needs", is to do "any human activity" that 
we choose to do. That is, we are not dealing with the narrow concept of "work" but with the general concept.

The possibility to divide the question into "technicality" and "meaning" can be demonstrated by asking a simple question. For example, were we to ask, "should humans work"? we would likely get a counter question that we could combine into the two categories (see schematic in Figure 1 ); 1 ) how would we make a living otherwise? (technical and practical question related to practical survival) or 2) what would we do otherwise? (philosophical question related to meaning or purpose).

We ran a small survey $(\mathrm{N}=30)$ to sketch and cluster the main concerns of people with work by asking the general question, openly and directly (see scheme in Figure 1A), "should humans work?" This question typically involved answers and counter questions related to technicalities and questions of meaning as shown in the scheme - see Annex and Table I for further details. We acknowledge that our survey is only illustrative in that we did not seek representing the whole population formally. Rather, we chose to present a small survey to briefly illustrate the kind of questions and answers that typically emerge when discussing the topic of human work and the advance of technology and automation. We also acknowledge that surveys with large and the proper samples representative of the population could or should be carried out in the future, but we argue that, for the purpose of our article here, our illustrative presentation is enough.

We note that we clearly stated to the participants that we referred to "paid work" as defined above, not to work in general as any human activity - see the Annex to read the actual statement. In general, it was 
possible to trace down whether people insisted in the concept of "work" per se, implying that they see work as a form of meaning, or whether they were more worried about the technical problem of survival. Some of the answers ambiguously claimed that we should work only in whatever we like in a way that somehow assumed that if we had enough money we could not do what we like. The actual relationship between humans and technology was never raised but, in our opinion, rather taken for granted or simply obviated. 
A)

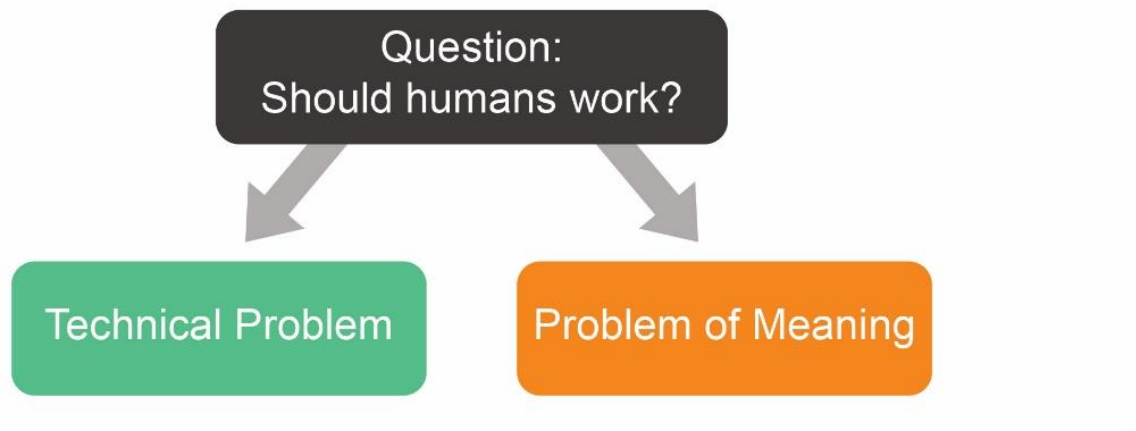

If you were given the option, would you: Change job as long as the salary was the same or higher.

Quit working overall as long as I had a salary or a source of income.

- Even if I had the salary guaranteed, I would do the same job.

B1)

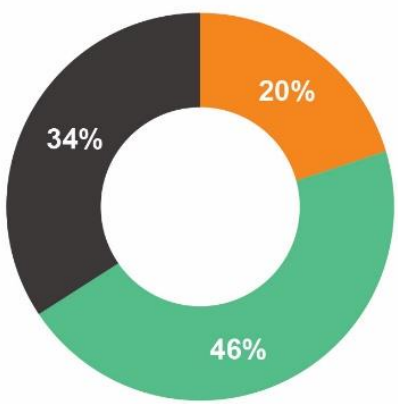

Facebook survey
B2)

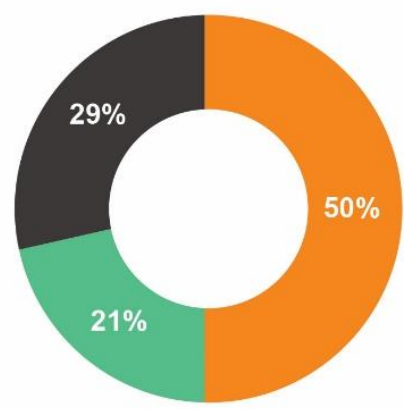

Harvard Graduate alumni survey

If we found a way for machines to do all jobs: I would not mind as long as I had access to money

$$
\text { I would not mind as long as I had access to whatever I need. }
$$

- I would mind because I want to work.

C1)

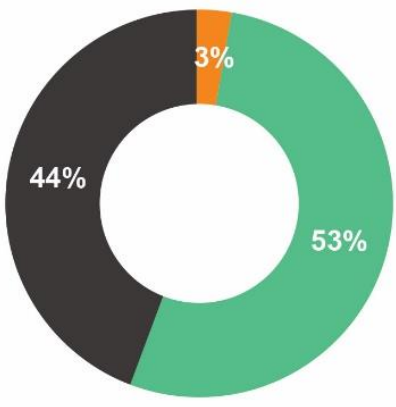

Facebook survey
C2)

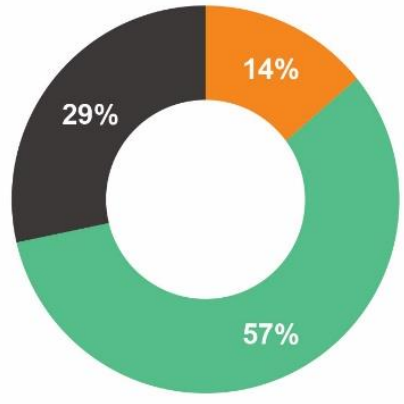

Harvard Graduate alumni survey

Figure 1. A) Scheme of the central question in this work and the grouping into two standard answers. B)

Results of a B1) and C1) survey in Facebook ( $N=34$ people answered the survey) ) and a B2) and C2) survey to Harvard graduate alumni at the Cambridge campus ( $\mathrm{N}=29$ people answered the survey). 
We further inspected beliefs and reasons behind these answers by asking the two questions below in 2 separate surveys. A general survey in Facebook with $\mathrm{N}=34$ participants (Figures $2 \mathrm{a}$ and $3 \mathrm{a}$ ) and a survey in an American University (Harvard, Cambridge, USA) campus ( $\mathrm{N}=29)$.

1. If you were given the option, would you (Figure 1B):

- Change job as long as the salary was the same or higher.

- Quit working overall as long as I had a salary or a source of income.

- Even if I had the salary guaranteed, I would do the same job.

2. If we found a way for machines to do all jobs (Figure 1C):

- I would not mind as long as I had access to money.

- I would not mind as long as I had access to whatever I need.

- I would mind because I want to work.

In short, our claim is that responses to the general question (Figure 1A) deal with the two different objects that we have detailed, in a way that, as far as we can tell, contain only artificial or spurious connections through the many times obfuscating terms "meaning" and "purpose". While defenders of the "meaning" and "purpose" of "work" sometimes claim that it is the term "work" that should be clarified, our claim is that the terms lacking ontological clarity are "meaning" and "purpose" instead. We particularly emphasize to those proponents the requirement to clarify the relation between "paid work" and "human activity" in terms of "meaning" and "purpose" in any human activity with a parameter other than the payment itself. This claim is the basis of our presupposition. Namely, that technical questions and questions of meaning or purpose can and should be separated. While we do not deny the relevance and importance of these complex terms, i.e. meaning, purpose (Damon, Menon, \& Cotton Bronk, 2003) or understanding of the "self" (Schlegel, Hicks, Arndt, \& King, 2009) within society, we also note that some already claim that the global establishment of $\mathrm{Al}$ and automation is motivated by the interests of powerful structures, sometimes via authoritarian practices(Lv \& Luo, 2018), and driven by 
financial or commercial interests(Liang, Das, Kostyuk, \& Hussain, 2018). It is further preposterous to claim that science and technology should not be allowed to accomplish a task, namely, reducing human work load, giving humans more free time to engage with their freedom and increasing access to basic needs to most or hopefully all, by invoking obscure terms such as "meaning" or "purpose" and assigning them in a seemingly exclusive manner to "work". It is a requirement that we clarify whether humans expect "goods" and "access to goods" and we give these tasks as priorities to technology to optimize these tasks, or whether we prioritize the terms "meaning" and "purpose" in relation to human "work".

Finally, regarding the question "should humans work?" and the answers and counter-questions that typically follow, we note the following. First, and regarding the technical question, we notice the absence of an explained fundamental role that "technology" might have, and whatever "advancing technology" might mean in modern society, in relation to humans accessing goods, that is, with human preoccupation with survival or meaning. That is, as we noted, technology might advance independently of whether most humans "survive". Second, and regarding the question of meaning, we also notice that "meaning" and "human activity" might come into the debate independently of whether "technology advances" as above defined. The "problem with technology" seems to be, in most cases, externally inserted into the debate by obviating that "technology must advance" in any case, as if on its own and as if advance did not relate to humans. What seems to act as a link between humans and technology is obscurely obviated by the relationship between 1) technology and an advancing efficiency of production and 2) the relationship between production, human jobs and survival. 


\section{Conclusions}

In summary, it is not clear whether people are afraid of losing their job, their salary or their access to the products and services that society offers, that is, "basic needs". It is not clear either whether people know what they should be afraid of should machines provide society with all goods and services required. In principle, and from the practical point of view of human well-being, covering the so-called "basic needs" does not require humans to have a "job" but simply "availability of goods" and then "access" to these goods. The solution to the question of how to produce and optimize access to goods, or basic needs, is therefore a political question and a question of social structure and ultimately an engineering and technical task to be carried out, and not a question of "meaning". We would go so far as to claim that even an optimization algorithm could more readily answer this question, i.e. how to provide enough to all, than a political debate or argument would, let alone the concept of meaning. Ultimately it seems illegitimate to the authors that the exploitation of ontologically unclear terms such as "meaning" and "purpose" are used to tell the technical fields whether they can meet a target or not. We propose that if there is a reason to underproducing that ranks higher than providing "basic needs" to all, such reason should be clarified and not hidden under the mysterious and ambiguous terms "meaning" or "purpose". Claiming that it is simply not possible right now to produce enough via technology alone is not a legitimate answer either since it does not clarify the objective, but rather states a fact. It seems to us that philosophy, politics and combinations of both should be exploited to unfold and pose the technical question while the technical fields should answer the technical question in 
terms of whether it has a technical solution or not. Instead of asking questions in the above orderly way, it seems that society is letting technology on the loose, so to speak, while hoping that some "jobs" will not be affected in order to preserve "meaning" to some and that most people won't be left in misery as technology advances. Targeting to increasing employment under such scenario further seems like a process of patching a problem when no direction is clear. This is particularly absurd if we take technology as a "tool" to make life easier and better. It seems like humans in general have not made up their mind as to whether they control technology or technology controls them. The overall impression is that humans do not want to take control over their future and prefer technical advances to lead the way as technical advances simply happen. It also remains unclear to what extent supporters of the "meaning" of jobs can justify supporting what could be inefficient, i.e. making humans do jobs that machines could carry out more efficiently, at the expense of producing insufficient goods to cover the "basic needs" of others, or simply, becoming an obstacle to the advance of science and technology. In terms of the technical aspect of work, suffice it to say as a summary that the solution to providing "goods" to humans only requires that society in general works toward the objective, i.e. becoming more efficient, by focusing on it as an "engineering" problem with a clear objective. That is, we believe that the solution to providing goods to humans is to be sought "technically". In this sense, we should not rush to conclusions as to whether, and based on the current state of the art of science and technology, or even current political or socially viable solutions, humans can do without working to meet the "basic needs" scheme. That is, the political, philosophical or social answer to this question is meant to provide a direction to technology rather than to ask technology at once whether it can provide a solution now. 
We finally propose that rather than animating a debate, even if a sophisticated one, that 1) currently leads and depends on obscure metaphysical terms such as "value", "control", "meaning", "purpose" or "advance" as well as on technical problems that correspond to the technical disciplines and 2) entertains the debate itself around the meaning of such terms to only 3) indirectly, and always depending on the previous, discuss the relationship between humans and technology. In short, it is precisely the relation that is to be explained. The implication is that we are to question what technology means to humans first to only then base the other terms, i.e. meaning, purpose or advance, and any technicalities like efficiency of production or other, on such relationship. As we have discussed throughout the article, from the abstract to this conclusions section, the lack of clarity regarding such relationship seems to allow for both humans and technology to part ways.

\section{References}

Adorno, T. W. (1991). The Culture Industry: Routledge.

Arntz, M., Gregory, T., \& Zierahn, U. (2017). Revisiting the risk of automation. Economics Letters, 159, 157-160.

Autor, D. H. (2015). Why Are There Still So Many Jobs? The History and Future of Workplace Automation. Journal of Economic Perspectives, 29, 3-30.

Bessen, J. (2016). How Computer Automation Affects Occupations: Technology, Jobs, and Skills. Boston Univ. School of Law, Law and Economics.

Bessen, J. (2018). Al and Jobs: the role of demand. National Bureau of Economic Research Working Paper Series.

Chomsky, N. (1998). The Common Good: Odonian Press.

Damon, W., Menon, J., \& Cotton Bronk, K. (2003). The Development of Purpose During Adolescence. Applied Developmental Science, 7, 119-128.

Foucault, M. (1994). The Order of Things: An Archaeology of the Human Sciences: Vintage.

Garimella, K. (2018). Job Loss From Al? There's More To Fear! In: Forbes.

Husserl, E. (2001). Logical Investigations: Routledge.

Jolly, R. (1976). The World Employment Conference: The Enthronement of Basic Needs. Development Policy Review, A9, 31-44.

Liang, F., Das, V., Kostyuk, N., \& Hussain, M. M. (2018). Constructing a Data-Driven Society: China's Social Credit System as a State Surveillance Infrastructure. Policy \& Internet, 10, 415-453. 
Lv, A., \& Luo, T. (2018). Authoritarian Practices in the Digital Age/ Asymmetrical Power Between Internet Giants and Users in China (Vol. 12).

Schlegel, R. J., Hicks, J. A., Arndt, J., \& King, L. A. (2009). Thine own self: True self-concept accessibility and meaning in life. Journal of Personality and Social Psychology, 96, 473-490.

technology, O. O. d. e. f. (2019). en.oxforddictionaries.com/definition/technology. In.

work, O. O. d. e. f. (2019). en.oxforddictionaries.com/definition/work. In. 